Yoichi Kawanishi · Shoji Harada • Hirokazu Tachikawa

Takehito Okubo $\cdot$ Hiroyasu Shiraishi

\title{
Novel variants in the promoter region of the CREB gene in schizophrenic patients
}

\begin{abstract}
Cyclic AMP-responsive element-binding protein (CREB) is one of the messenger molecules involved in intracellular signal transduction pathways used by most dopamine and serotonin receptor subtypes. In addition, CREB stimulates the expression of a number of genes, alterations in the expression of which may be associated with schizophrenia. The promoter region of the human CREB gene was therefore analyzed to identify genetic variants that may lead to the modification of CREB expression and contribute to schizophrenia. Eighty unrelated schizophrenics and 100 healthy controls were screened for genetic variants of the CREB gene by SSCP analysis, followed by direct sequencing of PCR products. Two novel variants $(-933 \mathrm{~T} \rightarrow \mathrm{C}$ and $-413 \mathrm{G} \rightarrow \mathrm{A})$ were found only in schizophrenics. A patient with the $-933 \mathrm{~T} \rightarrow \mathrm{C}$ variant had unusual clinical characteristics in addition to typical schizophrenic symptoms.
\end{abstract}

Key words cAMP-responsive element-binding protein . Transcription factor $\cdot$ Promoter $\cdot$ Variant $\cdot$ Schizophrenia Clinical characteristics

\section{Introduction}

The transcription factor cAMP-responsive element (CRE)binding protein (CREB) stimulates the transcription of a number of genes containing CREs (5'-TGACGTCA or similar motifs) in their promoter regions (Montminy 1997). These genes include somatostatin, dopamine D1 receptor, serotonin $2 \mathrm{~A}$ receptor, serotonin transporter, cholecystoki-

Y. Kawanishi $(\triangle) \cdot$ H. Tachikawa $\cdot$ H. Shiraishi

Department of Psychiatry, Institute of Clinical Medicine, University of Tsukuba, 1-1-1 Tennoudai, Tsukuba, Ibaraki 305-8575, Japan

Tel. +81-298-53-3274; Fax +81-298-53-3225

e-mail address: qb2y-kwns@asahi-net.or.jp

S. Harada $\cdot$ T. Okubo

Institute of Community Medicine, University of Tsukuba, Ibaraki, Japan nin, tyrosine hydroxylase, CREB, fos, proenkephalin, vasoactive intestinal peptide, and synapsin I (Meyer et al. 1993; Montminy 1997). Some of these genes are thought to be involved in schizophrenia in view of alterations in their expression in the central nervous system of schizophrenic patients (Burnet et al. 1996; Hernandez and Sokolov 1997). Moreover, CREB is one of the messenger molecules involved in intracellular signal transduction pathways used by most dopamine and serotonin receptor subtypes.

In light of its many roles in signal transduction and transcriptional regulation pathways that are thought to be involved in schizophrenia, it appears that the CREB gene itself may be a candidate gene for the disease. The present study focuses on the detection of nucleotide sequence variants in the promoter region of the human CREB gene, because such variants may affect CREB transcription and contribute to susceptibility to schizophrenia.

\section{Source and description}

Patients and controls

Written informed consent was obtained according to the research protocol approved by the Ethics Committee of Tsukuba University from 80 unrelated schizophrenics (mean age, $47.6 \pm 14.2$; mean age at onset, $26.9 \pm 9.1$ ) who met the DSM-IV criteria for schizophrenia, and from 100 unrelated healthy controls (mean age, $39.8 \pm 12.8$ ). All patients and controls were ethnic Japanese. Genomic DNA was prepared from whole blood samples according to methods described elsewhere (Kawanishi et al. 1998).

PCR

In describing the CREB gene promoter, the DNA sequence numbering given by Meyer et al. (1993) is used throughout. Three sets of PCR primers were used: CREB-UF (5'CCTGCTGTAGAAAACAGGCTG, nucleotide (nt) 


\section{SSCP analysis}
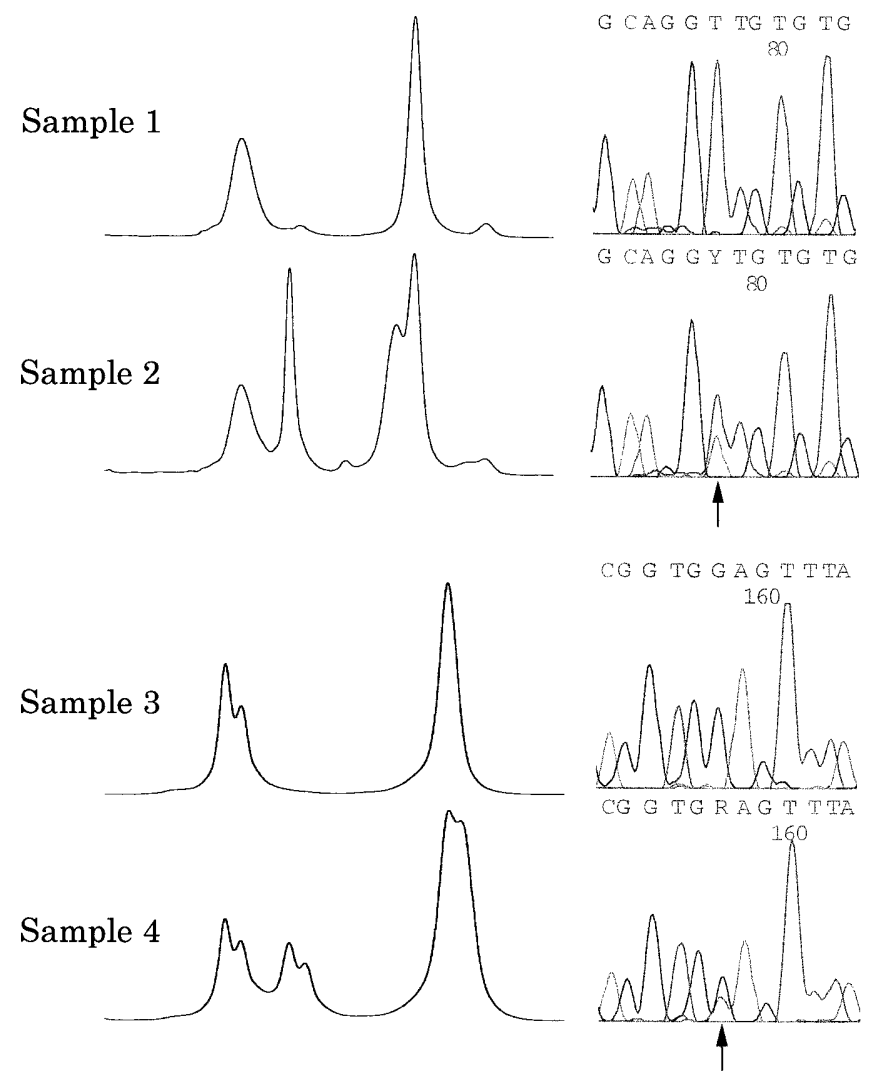

Fig. 1. SSCP analysis and direct sequencing of PCR products generated with the primer sets CREB-UF/CREB-UR (samples 1 and 2) and CREB-MF/CREB-MR (samples 3 and 4). Vertical arrows indicate the positions of nucleotide substitutions ( $\mathrm{Y}=\mathrm{C}$ or $\mathrm{T}, \mathrm{R}=\mathrm{A}$ or $\mathrm{G}$ ). Samples 1 and 3 show the homozygous wild-type; sample 2 shows the heterozygous genotype of the $-933 \mathrm{~T} \rightarrow \mathrm{C}$ variant, and sample 4 shows the heterozygous genotype of the $-413 \mathrm{G} \rightarrow \mathrm{A}$ variant

-1034 to -1014) and CREB-UR (5'-CGAGACTCCGCGGAAAAACC, nt -791 to -810); CREB-MF (5'TCAAGAGCAGAGCCAGGGCAG, nt -602 to -582 ) and CREB-MR (5'-GAAGGCGAAGGCGGGCTGAG, nt -365 to -384 ); and CREB-DF (5'-GTCGCCCGAAGAAACCCGAAG, nt -340 to -320 ) and CREB-DR (5'GTACAAGCTCCTCCGTCACTG, nt -14 to -34 ). PCR was carried out according to methods described elsewhere (Kawanishi et al. 1998), with the following modification: nested PCR (inner primers CREB-MF and CREB-MR) was performed using the outer primer pair CREB-UF and CREB-DR.

Single-strand conformation polymorphism (SSCP) analysis and sequencing

Fluorescence-based SSCP analysis and sequencing were performed according to methods described elsewhere (Kawanishi et al. 1998).
Variants and allele frequencies

Two novel variants $(-933 \mathrm{~T} \rightarrow \mathrm{C}$ and $-413 \mathrm{G} \rightarrow \mathrm{A})$ were identified in the promoter region of the CREB gene (Fig. 1). Each was identified in a different single schizophrenic patient with an allele frequency of $0.6 \%$, and both patients were heterozygotic for the variants. The $-413 \mathrm{G} \rightarrow \mathrm{A}$ variant was confirmed by RFLP analysis using $H p h \mathrm{I}$. Neither of the two variants was detected in the control group.

\section{Chromosomal localization}

The human CREB gene has been assigned to human chromosome 2q32.3-q34 (Taylor et al. 1990)

\section{Other comments}

Although the onset of disease occurred relatively early (at 15 years of age) in the male patient with the $-413 \mathrm{G} \rightarrow \mathrm{A}$ variant, there is nothing else of particular note in this case. In contrast, the female patient with the $-933 \mathrm{~T} \rightarrow \mathrm{C}$ variant had a family history of schizophrenia (uncle), and the onset of disease occurred earlier (at 13 years of age) than in any other patient in the present study. Moreover, this patient displayed some unusual clinical characteristics: electroencephalography disclosed slow wave abnormality although CT, MRI, and neurological examination were within normal limits, and the patient experienced visual hallucinations, conversion symptoms, and intellectual impairment (IQ 54 by WAIS-R testing) in addition to typical schizophrenic symptoms such as auditory hallucinations and persecutory delusions. WAIS-R analysis suggested that her intellectual impairment may have resulted from a reduced capacity to retain long-term memory. This might be related to the observation that mice with a targeted mutation of the CREB gene are profoundly deficient in longterm memory, showing no other overt abnormalities (Bourtchuladze et al. 1994).

\section{References}

Bourtchuladze R, Frenguelli B, Blendy J, Cioffi D, Schutz G, Silva AJ (1994) Deficient long-term memory in mice with a targeted mutation of the cAMP-responsive element-binding protein. Cell 79:59-68

Burnet PW, Eastwood SL, Harrison PJ (1996) $5-\mathrm{HT}_{1 \mathrm{~A}}$ and $5-\mathrm{HT}_{2 \mathrm{~A}}$ receptor mRNAs and binding site densities are differentially altered in schizophrenia. Neuropsychopharmacology 15:442-455

Hernandez I, Sokolov BP (1997) Abnormal expression of serotonin transporter mRNA in the frontal and temporal cortex of schizophrenics. Mol Psychiatry 2:57-64

Kawanishi Y, Harada S, Tachikawa H, Okubo T, Shiraishi H (1998) Novel mutations in the promoter and coding region of the human 5$\mathrm{HT}_{1 \mathrm{~A}}$ receptor gene and association analysis in schizophrenia. Am J Med Genet 81:434-439

Meyer TE, Waeber G, Lin J, Beckmann W, Habener JF (1993) The 
promoter of the gene encoding $3^{\prime}, 5^{\prime}$-cyclic adenosine monophosphate (cAMP) response element binding protein contains cAMP response elements: evidence for positive autoregulation of gene transcription. Endocrinology 132:770-780

Montminy M (1997) Transcriptional regulation by cyclic AMP. Annu
Rev Biochem 66:807-822

Taylor AK, Klisak I, Mohandas T, Sparkes RS, Li C, Gaynor R, Lusis AJ (1990) Assignment of the human gene for CREB1 to chromosome 2q32.3-q34. Genomics 7:416-421 